\title{
Bibliography
}

[1] Abramowitz, M. and Stegun, I.A. (1965), Handbook of Mathematical Functions with Formulae, Graphs and Mathematical Tables, National Bureau of Standards, Applied Math. Series 55, 4th printing, Washington.

[2] Acosta G. and Durán, R.G. (2003) An Optimal Poincaré inequality in $L_{1}$ for convex domains, Proc. A.M.S., Vol. 132 (1), 195-202.

[3] Adamski, W. (1991) An integral representation theorem for positive bilinear forms, Glasnik Matematicki, Ser III 26 (46), No. 1-2, 31-44.

[4] Agarwal, R.P. (1983) An Integro-Differential Inequality, General Inequalities, III (E.F. Beckenbach and W. Walter, eds.), Birkhäuser, Basel, 501-503.

[5] Agarwal, R.P. (2000) Difference Equations and Inequalities. Theory, Methods and Applications, Second Edition, Monographs and Textbooks in Pure and Applied Mathematics, 228. Marcel Dekker, Inc., New York.

[6] Agarwal R.P. and Pang, P.Y.H. (1995) Opial Inequalities with Applications in Differential and Difference Equations, Kluwer Academic Publishers, Dordrecht, Boston, London.

[7] Agarwal, R.P. and Wong, P.J.Y (1993) Error Inequalities in Polynomial Interpolation and their Applications, Mathematics and its Applications, 262, Kluwer Academic Publishers, Dordrecht, Boston, London.

[8] Aliprantis, C.D. and Burkinshaw, O. (1998) Principles of Real Analysis, third edition, Academic Press, Boston, New York.

[9] Aljinovic, A.A., Dedic, Lj., Matic, M. and Pecaric, J. (2005) On Weighted Euler harmonic Identities with Applications, Mathematical Inequalities and Applications, 8, No. 2, 237-257.

[10] Aljinovic, A.A., Matic, M. and Pecaric, J. (2005) Improvements of some Ostrowski type inequalities, J. of Computational Analysis and Applications, 7, No. 3, 289-304.

[11] Aljinovic, A.A. and Pecaric, J. (2005) The weighted Euler identity, Mathematical Inequalities and Applications, 8, No. 2, 207-221.

[12] Aljinovic, A.A. and Pecaric, J. (2007) Generalizations of weighted Euler Identity and Ostrowski type inequalities, Adv. Stud. Contemp. Math. (Kyungshang) 14, No. 1, $141-151$.

[13] Aljinovic, A.A., Pecaric, J. and Vukelic, A. (2005) The extension of Montgomery identity via Fink identity with applications, Journal of Inequalities and Applications, Vol. 2005, No. 1, 67-80.

[14] Alon, N. and Naor, A. (2006) Approximating the cut-norm via Grothendieck's inequality, SIAM J. Comput., 35, No. 4, 787-803 (electronic).

[15] Anastassiou, G.A. (1993) Moments in Probability and Approximation Theory, Pitman Research Notes in Math., 287, Longman Sci. and Tech., Harlow, U.K. 
[16] Anastassiou, G.A. (1995) Ostrowski type inequalities, Proc. AMS, 123, 3775-3781.

[17] Anastassiou, G.A. (1997) Multivariate Ostrowski type inequalities, Acta Math. Hungarica, 76, No. 4, 267-278.

[18] Anastassiou, G.A. (1998) Opial type inequalities for linear differential operators, Mathematical Inequalities and Applications, 1, No. 2, 193-200.

[19] Anastassiou, G.A. (1998) General fractional Opial type inequalities, Acta Applicandae Mathematicae, 54, No. 3, 303-317.

[20] Anastassiou, G.A. (1999) Opial type inequalities involving fractional derivatives of functions, Nonlinear Studies, 6, No. 2, 207-230.

[21] Anastassiou, G.A. (2001) Quantitative Approximations, Chapman and Hall/CRC, Boca Raton, New York.

[22] Anastassiou, G.A. (2001) Taylor integral remainders and moduli of smoothness, Y.Cho, J.K.Kim and S.Dragomir (eds.), Inequalities Theory and Applications, 1, Nova Science Publ., New York, 1-31.

[23] Anastassiou, G.A. (2002) Multidimensional Ostrowski inequalities, revisited, Acta Mathematica Hungarica, 97, No. 4, 339-353.

[24] Anastassiou, G.A. (2002) Univariate Ostrowski inequalities, revisited, Monatshefte Math., 135, 175-189.

[25] Anastassiou, G.A. (2002) Multivariate Montgomery identities and Ostrowski inequalities, Numer. Funct. Anal. and Opt., 23, No. 3-4, 247-263.

[26] Anastassiou, G.A. (2002) Integration by parts on the Multivariate domain, Annals of University of Oradea, fascicola mathematica, Tom IX, 5-12.

[27] Anastassiou, G.A. (2003) On Grüss type multivariate integral inequalities, Mathematica Balkanica, New Series Vol. 17, Fasc.1-2, 1-13.

[28] Anastassiou, G.A. (2003) A new expansion formula, Cubo Matematica Educational, 5, No. 1, 25-31.

[29] Anastassiou, G.A. (2006) Multivariate Euler type identity and Ostrowski type inequalities, Proceedings of the International Conference on Numerical Analysis and Approximation theory, NAAT 2006, Cluj-Napoca (Romania), July 5-8, 27-54.

[30] Anastassiou, G.A. (2006) Difference of general integral means, Journal of Inequalities in Pure and Applied Mathematics, 7, No. 5, Article 185, pp. 13, http://jipam.vu.edu.au.

[31] Anastassiou, G.A. (2007) Opial type inequalities for semigroups, Semigroup Forum, 75, 625-634.

[32] Anastassiou, G.A. (2007) On Hardy-Opial Type Inequalities, J. of Math. Anal. and Approx. Th., 2 (1), 1-12.

[33] Anastassiou, G.A. (2007) Chebyshev-Grüss type and comparison of integral means inequalities for the Stieltjes integral, Panamerican Mathematical Journal, 17, No. 3, 91-109.

[34] Anastassiou, G.A. (2007) Multivariate Chebyshev-Gr üss and comparison of integral means type inequalities via a multivariate Euler type identity, Demonstratio Mathematica, 40, No. 3, 537-558.

[35] Anastassiou, G.A. (2007) High order Ostrowski type Inequalities, Applied Math. Letters, 20, 616-621.

[36] Anastassiou, G.A. (2007) Opial type inequalities for Widder derivatives, Panamer. Math. J., 17, No. 4, 59-69.

[37] Anastassiou, G.A. (2007) Grüss type inequalities for the Stieltjes Integral, J. Nonlinear Functional Analysis and Appls., 12, No. 4, 583-593.

[38] Anastassiou, G.A. (2007) Multivariate Euler type identity and optimal multivariate Ostrowski type inequalities, Advances in Nonlinear Variational Inequalities, 10, No. 2, 51-104. 
[39] Anastassiou, G.A. (2007) Multivariate Fink type identity and multivariate Ostrowski, comparison of means and Grüss type inequalities, Mathematical and Computer Modelling, 46, 351-374.

[40] Anastassiou, G.A. (2007) Optimal multivariate Ostrowski Euler type inequalities, Studia Univ. "Babes-Bolyai", ser. Mathematica, Vol. LII, No. 1, 25-61.

[41] Anastassiou, G.A. (2007) Chebyshev-Grüss type inequalities via Euler type and Fink identities, Mathematical and Computer Modelling, 45, 1189-1200.

[42] Anastassiou, G.A. (2007) Ostrowski type inequalities over balls and shells via a TaylorWidder formula, JIPAM, J. Inequal. Pure Appl. Math., 8, No. 4, Article 106, 13 pp.

[43] Anastassiou, G.A. (2008) Representations of functions, Nonlinear Functional Analysis and Applications, 13, No. 4, 537-561.

[44] Anastassiou, G.A. (2008) Poincaré and Sobolev type inequalities for vector valued functions, Computers and Mathematics with Applications, 56, 1102-1113.

[45] Anastassiou, G.A. (2008) Opial type inequalities for cosine and sine operator functions, Semigroup Forum, 76, No. 1, 149-158.

[46] Anastassiou, G.A. (2008) Chebyshev-Grüss type inequalities on $\mathbb{R}^{N}$ over spherical shells and balls, Applied Math. Letters, 21, 119-127.

[47] Anastassiou, G.A. (2008) Ostrowski type inequalities over spherical shells, Serdica Math. J., 34, 629-650.

[48] Anastassiou, G.A. (2008) Poincare type Inequalities for linear differential operators, CUBO, 10, No. 3, 13-20.

[49] Anastassiou, G.A. (2008) Grothendieck type inequalities, Applied Math. Letters, 21, 1286-1290.

[50] Anastassiou, G.A. (2009) Poincaré like inequalities for semigroups, cosine and sine Operator functions, Semigroup Forum, 78, 54-67.

[51] Anastassiou, G.A. (2009) Distributional Taylor formula, Nonlinear Analysis, 70, 31953202.

[52] Anastassiou, G.A. (2008) Opial type inequalities for vector valued functions, Bulletin of Hellenic Mathematical Society, 55, 1-8.

[53] Anastassiou, G.A. (2009) Fractional Differentiation Inequalities, Springer Verlag, Berlin - New York, 693 pp.

[54] Anastassiou, G.A. (2009) Poincaré and Sobolev type inequalities for Widder derivatives, Demonstratio Mathematica, 42, No. 2, 283-296.

[55] Anastassiou G.A. and Dragomir, S.S. (2001) On some estimates of the remainder in Taylor's formula, J. of Math. Analysis and Appl., 263, 246-263.

[56] Anastassiou G.A. and Goldstein, J. (2007) Ostrowski type inequalities over Euclidean domains, Rend. Lincei Mat. Appl., 18, 305-310.

[57] Anastassiou G.A. and Goldstein, J. (2008) Higher order Ostrowski type inequalities over Euclidean domains, Journal of Math. Anal. Appl.,337, 962-968.

[58] Anastassiou, G.A., Goldstein, G.R. and Goldstein, J.A. (2004) Multidimensional Opial inequalities for functions vanishing at an interior point, Atti Accad. Lincei Cl. Fis. Mat. Natur. Rend. Math. Acc. Lincei, s. 9, v. 15, 5-15.

[59] Anastassiou, G.A., Goldstein, G.R. and Goldstein, J.A. (2006)Multidimensional weighted Opial inequalities, Applicable Analysis, 85, No. 5, 579-591.

[60] Anastassiou G.A. and Papanicolaou, V. (2002) A new basic sharp integral inequality, Revue Roumaine de Mathematiques Pure et Appliquees, 47, 399-402.

[61] Anastassiou G.A. and Pecaric, J. (1999) General weighted Opial inequalities for linear differential operators, J. Mathematical Analysis and Applications, 239, No. 2, 402418.

[62] Apostol, T.M. (1974) Mathematical Analysis, Second Edition, Addison-Wesley Publ. Co. 
[63] Aumann, S., Brown, B.M. and Schmidt, K.M. (2008) A Hardy-Littlewood-type inequality for the $p$-Laplacian, Bull. Lond. Math. Soc., 40, No. 3, 525-531.

[64] Azar, L.E. (2008) On some extensions of Hardy-Hilbert's inequality and applications, J. Inequal. Appl., Art. ID 546829, 14 pp.

[65] Bainov D. and Simeonov, P. (1992) Integral Inequalities and Applications, translated by R. A. M. Hoksbergen and V. Covachev, Mathematics and its Applications (East European Series), 57, Kluwer Academic Publishers Group, Dordrecht.

[66] Bakry, D., Barthe, F., Cattiaux, P. and Guilin, A. (2008) A simple proof of the Poincaré inequality for a large class of probability measures including the log-concave case, Electron. Commun. Probab., 13, 60-66.

[67] Bao, G., Xing, Yuming and Wu, Congxin (2007) Two-weight Poincaré inequalities for the projection operator and A-harmonic tensors on Riemannian manifolds, Illinois J. Math., 51, No. 3, 831-842.

[68] Barnett, N.S., Cerone, P. and Dragomir, S.S. (2001) Ostrowski type inequalities for multiple integrals, pp. 245-281, Chapter 5 from Ostrowski Type Inequalities and Applications in Numerical Integration, edited by S. S. Dragomir and T. Rassias, on line: http://rgmia.vu.edu.au/monographs, Melbourne.

[69] Barnett N.S. and Dragomir, S.S. (1998) An inequality of Ostrowski's type for cumulative distribution functions, RGMIA (Research Group in Mathematical Inequalities and Applications), Vol. 1, No. 1, pp. 3-11, on line: http://rgmia.vu.edu.au

[70] Barnett N.S. and Dragomir, S.S. (1998) An Ostrowski type inequality for double integrals and applications for cubature formulae, RGMIA Research Report Collection, 1, 13-22.

[71] Barnett N.S. and Dragomir, S.S. (1998) An Ostrowski type inequality for a random variable whose probability density function belongs to $\mathrm{L}_{\infty}[a, b], R G M I A$ Research Group in Mathematical Inequalities and Applications, Vol. 1, No. 1, pp. 23-31, on line: http://rgmia.vu.edu.au

[72] Barnett N.S. and Dragomir, S.S. (2001) An Ostrowski type inequality for double integrals and applications for cubature formulae, Soochow J. Math., 27, No. 1, 1-10.

[73] Barnett, N.S. and Dragomir, S.S. (2007) On the weighted Ostrowski inequality. JIPAM, J. Inequal. Pure Appl. Math., 8, No. 4, Article 96, pp. 10.

[74] Bartle, R.G. (1976) The Elements of Real Analysis, Second Edition, Wiley, New York.

[75] Beesack, P.R. (1962) On an integral inequality of Z. Opial, Trans. Amer. Math. Soc., 104, 479-475.

[76] Bohner, M. and Matthews, T. (2008) Ostrowski inequalities on time scales, JIPAM, J. Inequal. Pure Appl. Math., 9, no. 1, Article 6, pp. 8.

[77] Burenkov, V.I. (1974) Sobolev's integral representation and Taylor's formula, (Russian), Studies in the theory of differentiable functions of several variables and its applications, V. Trudy Mat. Inst. Steklov., 131, 33-38.

[78] Burenkov, V.I. (1998) Sobolev Space on Domains, Teubner-Texte zur Mathematik [Teubner Texts in Mathematics], 137. B. G. Teubner Verlagsgesellschaft mbtt, Stuttgart, pp. 312.

[79] Butzer, P.L. and Berens, H. (1967) Semi-Groups of Operators and Approximation, Springer-Verlag, New York.

[80] Butzer, P.L. and Tillmann, H.G. (1960) Approximation theorems for semigroups of bounded linear transformations, Math. Annalen, 140, 256-262.

[81] Canavati, J.A. (1987) The Riemann-Liouville integral, Nieuw Archief Voor Wiskunde, 5, No. 1, 53-75.

[82] Cerone, P. (2002) Difference between weighted integral means, Demonstratio Mathematica, Vol. 35, No. 2, pp. 251-265. 
[83] Cerone, P. (2003) Approximate multidimensional integration through dimension reduction via the Ostrowski functional, Nonlinear Funct. Anal. Appl., 8, No. 3, 313-333.

[84] Cerone, P. and Dragomir, S.S. (2000) Trapezoidal-type rules from an inequalities point of view, Chapter 3 in Handbook of Analytical-Computational Methods in Applied Mathematics, edited by George Anastassiou, Chapman and Hall/CRC, pp. 65-134.

[85] Cerone, P. and Dragomir, S.S. (2000) Midpoint type rules from an inequality point of view, Chapter 4 in Handbook of Analytical-Computational Methods in Applied Mathematics, edited by George Anastassiou, Chapman and Hall/CRC, pp. 135-200.

[86] Cerone, P. and Dragomir S.S (2004) and Ferdinand Österreicher, Bounds on extended f-divergences for a variety of classes, Kybernetika (Prague), 40, No. 6, 745-756.

[87] Cerone, P. and Dragomir, S.S. (2008) Advances in Inequalities for Special Functions, edited volume, Nova Publ., New York.

[88] Chebyshev, P.L. (1882) Sur les expressions approximatives des integrales definies par les autres prises entre les mêmes limites, Proc. Math. Soc. Charkov, 2, 93-98.

[89] Cheung, W.-S. and Zhao, C.-J. (2007) On a discrete Opial-type inequality, JIPAM, J. Inequal. Pure Appl. Math., 8, No. 4, Article 98, pp. 4.

[90] Cheung, Wing-Sum and Zhao, Chang-Jian (2007) On Opial-type integral inequalities, J. Inequal. Appl., Art. ID 38347, pp. 15.

[91] Cheung, W.-S., Dandan, Zhao and Pecaric, J. (2007) Opial-type inequalities for differential operators, Nonlinear Anal., 66, No. 9, 2028-2039.

[92] Chua, S.-K. and Wheeden, R.L. (2006) A note on sharp 1-dimensional Poincaré inequalities, Proc. AMS, Vol. 134, No. 8, 2309-2316.

[93] Chyan, D.-K., Shaw, S.-Y. and Piskarev, S. (1999) On Maximal regularity and semivariation of Cosine operator functions, J. London Math. Soc., (2) 59, 1023-1032.

[94] Cianchi, A. (2008) Sharp Morrey-Sobolev inequalities and the distance from extremals, Trans. Amer. Math. Soc., 360, No. 8, 4335-4347.

[95] Cianchi, A. and Ferone, A. (2008) A strengthened version of the Hardy-Littlewood inequality, J. Lond. Math. Soc. (2) 77, No. 3, 581-592.

[96] Civljak, A., Dedic, Lj. and Matic, M. (2007) On Ostrowski and Euler-Grüss type inequalities involving measures, J. Math. Inequal., 1, No. 1, 65-81.

[97] Cho, H.R. and Lee, J. (2005) Inequalities for the integral means of holomorphic functions in the strongly pseudoconvex domain, Commun. Korean Math. Soc., 20, No. 2, 339-350.

[98] Dedic, Lj., Matic, M. and Pecaric, J. (2000) On generalizations of Ostrowski inequality via some Euler- type identities, Mathematical Inequalities and Applications, Vol. 3, No. 3, 337-353.

[99] Dedic, Lj., Matic, M., Pecaric, J. and Vukelic, A. (2002) On generalizations of Ostrowski inequality via Euler harmonic identities, Journal of Inequalities and Applications, Vol. 7, No. 6, 787-805.

[100] Draghici, C. (2006) Inequalities for integral means over symmetric sets, J. Math. Anal. Appl., 324, No. 1, 543-554.

[101] Dragomir, S.S. (1999) New estimation of the remainder in Taylor's formula using Grüss' type inequalities and applications, Math. Ineq. Appl., 2(2), 183-193.

[102] Dragomir, S.S. (2001) Ostrowski's inequality for mappings of bounded variation and applications, Math. Ineq. and Appl., 4 (1), 59-66, and on-line in (http://rgmia.vu.edu.au); RGMIA Res. Rep. Coll., 2 (1) (1999), 103-110.

[103] Dragomir, S.S. (2000) A Survey on Cauchy-Buniakowsky-Schwartz Type Discrete Inequalities, RGMIA Monographs, Victoria University. (on-line http://rgmia.vu.edu.au/monographs/). 
[104] Dragomir, S.S. (2000) Semi-Inner Products and Applications, RGMIA Monographs, Victoria University. (on-line http://rgmia.vu.edu.au/monographs/).

[105] Dragomir, S.S. (2000) Some Gronwall Type Inequalities and Applications, RGMIA Monographs, Victoria University. (on-line http://rgmia.vu.edu.au/monographs/).

[106] Dragomir, S.S. (2000) Some inequalities of Grüss type, Indian J. Pure Appl. Math., 31, 397-415.

[107] Dragomir, S.S. (2002) New estimates of the Čebyšev functional for Stieltjes integrals and applications, RGMIA, 5, Supplement Article 27, electronic, http://rgmia.vu.edu.au

[108] Dragomir, S.S. (2002) Sharp bounds of Čebyšev functional for Stieltjes integrals and applications, RGMIA, 5, Supplement Article 26, electronic, http://rgmia.vu.edu.au

[109] Dragomir, S.S. (2003) Some Gronwall Type Inequalities and Applications, Nova Science Publishers, Inc., Hauppauge, NY.

[110] Dragomir, S.S. (2003) A weighted Ostrowski type inequality for functions with values in Hilbert spaces and Applications, J. Korean Math. Soc., 40, 207-224.

[111] Dragomir, S.S. (2004) Semi-Inner Products and Applications, Nova Science Publishers, Inc., Hauppauge, NY.

[112] Dragomir, S.S. (2004) Discrete Inequalities of the Cauchy-Bunyakovsky-Schwarz Type, Nova Science Publishers, Inc., Hauppauge, NY.

[113] Dragomir, S.S. (2004) Inequalities of Grüss type for the Stieltjes integral and applications, Kragujevac J. Math., 26, 89-122.

[114] Dragomir, S.S. (Ed.) (2004), Advances in inequalities of the Schwarz, Grüss and Bessel Type in Inner Product Spaces, RGMIA Monographs, Victoria University. (online http://rgmia.vu.edu.au/monographs/).

[115] Dragomir, S.S. (Ed.) (2005) Advances in Inequalities of the Schwarz, Triangle and Heisenberg Type in Inner Product Spaces, RGMIA Monographs, Victoria University. (on-line http://rgmia.vu.edu.au/monographs/).

[116] Dragomir, S.S. (2005) Advances in inequalities of the Schwarz, Grüss and Bessel Type in Inner Product Spaces, Nova Science Publishers, Inc., Hauppauge, NY.

[117] Dragomir, S.S. (2007) Advances in Inequalities of the Schwarz, Triangle and Heisenberg Type in Inner Product Spaces, Nova Science Publishers, Inc., Hauppauge, NY.

[118] Dragomir, S.S. (2007) Grüss type discrete inequalities in inner product spaces, revisited, Inequality theory and applications, Vol. 5, Nova Sci. Publ., NY, 61-69.

[119] Dragomir, S.S. (2007) Sharp Grüss-type inequalities for functions whose derivatives are of bounded variation, JIPAM, J. Inequal. Pure Appl. Math., 8, No. 4, Article 117 , pp. 13.

[120] Dragomir, S.S. and Barnett, N.S. (1998) An Ostrowski type inequality for mappings whose second derivatives are bounded and applications, RGMIA Research Report Collection, Vol. 1, No. 2, 69-77, on line http://rgmia.vu.edu.au

[121] Dragomir, S.S. and Barnett, N.S. (1999) An Ostrowski type inequality for mappings whose second derivatives are bounded and applications, J. Indian Math. Soc. (S.S.), 66 (1-4), 237-245.

[122] Dragomir, S.S., Barnett, N.S. and Cerone, P. (1998) An Ostrowski type inequality for double integrals in terms of $L_{p}$-norms and applications in numerical integration, RGMIA Research Report Collection, Vol.1, No. 2, 79-87, on line http://rgmia.vu.edu.au

[123] Dragomir, S.S., Barnett, N.S. and Cerone, P. (1999) An $n$-dimension version of Ostrowski's inequality for mappings of the Holder Type, RGMIA Res. Rep. Collect, 2, 169-180. 
[124] Dragomir, S.S., Barnett, N.S. and Cerone, P. (2000) An $n$-dimensional version of Ostrowski's inequality for mappings of the Hölder type, Kyungpook Math. J., 40, No. 1, 65-75.

[125] Dragomir, S.S., Cerone, P., Barnett, N.S. and Roumeliotis, J. (1999) An inequality of the Ostrowski type for double integrals and applications to cubature formulae, RGMIA Research Report Collection, 2, 781-796.

[126] Dragomir, S.S., Cerone, P., Barnett, N.S. and Roumeliotis, J. (2000) An inequality of the Ostrowski type for double integrals and applications to cubature formulae, Tamsui Oxford Journal of Mathematical Sciences, 16, 1-16.

[127] Dragomir, S.S. and Gosa, A.C. (2007) A generalization of an Ostrowski inequality in inner product spaces, in: Inequality Theory and Applications, Vol. 4, 61-64, Nova Sci. Publ., New York.

[128] Dragomir, S.S. and Pearce, C.E.M. (2000) Selected Topics on Hermite-Hadamard Inequalities and Applications, RGMIA Monographs, Victoria University. (on-line http://rgmia.vu.edu.au/monographs/).

[129] Dragomir, S.S. and Pecaric, J. (1989) Refinements of some inequalities for isotonic functionals, Anal. Num. Theor. Approx., 11, 61-65.

[130] Dragomir, S.S., Pečarić, J.E. and Tepes, B. (2007) Note on integral version of the Grüss inequality for complex functions, in: Inequality Theory and Applications, Vol. 5, 91-96, Nova Sci. Publ., New York.

[131] Dragomir, S.S. and Rassias, T.M. (2000) Ostrowski Type Inequalities and Applications in Numerical Integration, RGMIA Monographs, Victoria University. (on-line http://rgmia.vu.edu.au/monographs/).

[132] Dudley, R.M. (1989) Real Analysis and Probability, Wadsworth and Brooks/Cole, Pacific Grove, CA.

[133] J. Duoandikoetxea, J. (2001) A unified approach to several inequalities involving functions and derivatives, Czechoslovak Mathematical Journal, 51 (126), 363-376.

[134] Durán, A.L., Estrada, R. and Kanwal, R.P. (1996) Pre-asymptotic expansions, J. of Math. Anal. and Appl., 202, 470-484.

[135] Estrada, R. and Kanwal, R.P. (1990) A Distributional theory for asymptotic expansions, Proceedings of the Royal Society of London, Series A, Mathematical and Physical Sciences, Vol. 428, No. 1875, 399-430.

[136] Estrada, R. and Kanwal, R.P. (1992) The asymptotic expansion of certain multidimensional generalized functions, J. of Math. Analysis and Appl., 163, 264-283.

[137] Estrada, R. and Kanwal, R.P. (1993) Taylor expansions for distributions, Mathematical Methods in the Applied Sciences, Vol. 16, 297-304.

[138] Estrada, R. and Kanwal, R.P. (2002) A Distributional Approach to Asymptotics, Theory and Applications, 2nd Edition, Birkhäuser, Boston, Basel, Berlin.

[139] Evans, L.C. (1998) Partial Differential Equations, Graduate Studies in Mathematics, vol. 19, American Mathematical Society, Providence, RI.

[140] Fattorini, H.O. (1968) Ordinary differential equations in linear topological spaces, Int. J. Diff. Equations, 5, 72-105.

[141] Fink, A.M. (1992) Bounds on the deviation of a function from its averages, Czechoslovak Mathematical Journal, 42 (117), No. 2, 289-310.

[142] Fleming, W. (1977) Functions of Several Variables, Springer-Verlag, New York, Berlin, Undergraduate Texts in Mathematics, 2nd edition.

[143] Flores-Franulič, A. and Romá n-Flores, H. (2007) A Chebyshev type inequality for fuzzy integrals, Appl. Math. Comput., 190, No. 2, 1178-1184.

[144] Gao, Peng (2008) Hardy-type inequalities via auxiliary sequences, J. Math. Anal. Appl., 343, No. 1, 48-57. 
[145] Gavrea, I. (2006) On Chebyshev type inequalities involving functions whose derivatives belong to $\mathrm{L}_{p}$ spaces via isotonic functionals, JIPAM, J. Inequal. Pure Appl. Math., 7, No. 4, Article 121, 6 pp. (electronic).

[146] Gel'fand, I.M. and Shilov, G.E. (1964) Generalized Functions, Vol. I, Academic Press, New York, London.

[147] Goldstein, J.A. (1985) Semigroups of Linear Operators and Applications, Oxford Univ. Press, Oxford.

[148] Goyal, S.P. (2007) Manita Bhagtani and Kantesh Gupta, Integral mean inequalities for fractional calculus operators of analytic multivalent function, Bull. Pure Appl. Math., 1, No. 2, 214-226.

[149] Grothendieck, A. (1956) Résumé de la th éorie métrique des produits tensoriels topologiques, Bol. Soc. Matem. São Paolo, 8, 1-79.

[150] Grüss, G. (1935) Über das Maximum des absoluten Betrages von

$$
\left[\left(\frac{1}{b-a}\right) \int_{a}^{b} f(x) g(x) d x-\left(\frac{1}{(b-a)^{2}} \int_{a}^{b} f(x) d x \int_{a}^{b} g(x) d x\right)\right],
$$

Math. Z., 39, pp. 215-226.

[151] Güney, H. Ö. and Owa, S. (2007) Integral means inequalities for fractional derivatives of a unified subclass of prestarlike functions with negative coefficients, J. Inequal. Appl., Art. ID 97135, 9 pp.

[152] Guyker, J. (2006) An inequality for Chebyshev connection coefficients, JIPAM, J. Inequal. Pure Appl. Math., 7, No. 2, Article 67, 11 pp. (electronic).

[153] Haagerup, U. (1987) A new upper bound for the complex Grothendieck constant, Israel J. Math., 60, 199-224.

[154] Haluska, J. and Hutnik, O. (2007) Some inequalities involving integral means, Tatra Mt. Math. Publ., 35, 131-146.

[155] Han, J. (2008) A class of improved Sobolev-Hardy inequality on Heisenberg groups, Southeast Asian Bull. Math., 32, No. 3, 437-444.

[156] Hardy, G.H., Littlewood, J.E. and Polya, G. (1988) Inequalities, Reprint of the 1952 edition, Cambridge Mathematical Library, Cambridge University Press, Cambridge.

[157] Harjulehto, P. and Hurri-Syrjanen, R. (2008) On a (q,p)-Poincaré inequality, J. Math. Anal. Appl., 337, No. 1, 61-68.

[158] Hewitt, E. and Stromberg, K. (1965) Real and Abstract Analysis, Springer-Verlag, New York, Berlin.

[159] Hille, E. and Phillips, R.S. (1957) Functional Analysis and Semigroups, revised edition, pp. XII a. 808, Amer. Math. Soc. Colloq. Publ., Vol. 31, Amer. Math. Soc., Providence, RI.

[160] Hognas, G. (1977) Characterization of weak convergence of signed measures on [0,1], Math. Scand., 41, 175-184.

[161] Johnson, J. (1985) An elementary characterization of weak convergence of measures, The American Math. Monthly, 92, No. 2, 136-137.

[162] Junge, M. (2005) Embedding of the operator space OH and the logarithmic little Grothendieck inequality, Invent. Math., 161, No. 2, 225-286.

[163] Karlin, S. and Studden, W.J. (1966) Tchebycheff Systems: with Applications in Analysis and Statistics, Interscience, New York.

[164] Katznelson, Y. (1976) An introduction to Harmonic Analysis, Dover, New York.

[165] Keith, S. and Zhong, Xiao (2008) The Poincaré inequality is an open ended condition, Ann. of Math., (2) 167, No. 2, 575-599.

[166] Kemperman, J.H.B. (1965) On the sharpness of Tchebycheff type inequalities, Indagationes Math., 27, 554-601. 
[167] Kingman, J. and Taylor, S. (1966) Introduction to Measure and Probability, Cambridge University Press, Cambridge, NY.

[168] Korovkin, P.P. (1986) Inequalities, Translated from the Russian by Sergei Vrubel, Reprint of the 1975 edition, Little Mathematics Library, Mir, Moscow, distributed by Imported Publications, Chicago, IL.

[169] Kreider, D., Kuller, R., Ostberg, D. and Perkins, F. (1966) An Introduction to Linear Analysis, Addison-Wesley Publishing Company, Inc., Reading, Mass., USA.

[170] Krivine, I.L. (1977) Sur la constante de Grothendieck, Comptes Rendus Acad. Sci. Paris, 284, 445-446.

[171] Krylov, V.I. (1962) Approximate Calculation of Integrals, Macmillan, New York, London.

[172] Kwong, M.K. (2007) On an Opial inequality with a boundary condition, JIPAM, J. Inequal. Pure Appl. Math., 8, No. 1, Article 4, 6 pp. (electronic).

[173] Lakshmikantham, V. and Leela, S. (1969) Differential and Integral Inequalities: Theory and Applications, vol. I: Ordinary Differential Equations, Mathematics in Science and Engineering, Vol. 55-I, Academic Press, New York - London.

[174] Lakshmikantham, V. and Leela, S. (1969) Differential and Integral Inequalities: Theory and Applications, vol. II: Functional, Partial, Abstract and Complex Differential Equations, Mathematics in Science and Engineering, Vol. 55-II, Academic Press, New York - London.

[175] Lehrbäck, J. (2008) Pointwise Hardy inequalities and uniformly fat sets, Proc. Amer. Math. Soc., 136, No. 6, 2193-2200.

[176] Levinson, N. (1964) On an inequality of Opial and Beesack, Proc. Amer. Math. Soc., 15, 565-566.

[177] Lian, W.-C., Yu, S.-L., Wong, F.-H. and Lin, S.-W. (2005) Nonlinear type of Opial's inequalities on time scales, Int. J. Differ. Equ. Appl., 10, No. 1, 101-111.

[178] Lieb, E.H. and Loss, M. (2001) Analysis, 2nd Edition, American Math. Soc., Providence, R. I.

[179] Lin, C.T. and Yang, G.S. (1983) A generalized Opial's inequality in two variables, Tamkang J. Math., 15, 115-122.

[180] Liu, W. and Dong, J. (2008) On new Ostrowki type inequalities, Demonstratio Math., 41, No. 2, 317-322.

[181] Liu, Zheng (2007) Notes on a Grüss type inequality and its application, Vietnam J. Math., 35, No. 2, 121-127.

[182] Lust-Piquard, F. and Xu, Q. (2007) The little Grothendieck theorem and Khintchine inequalities for symmetric spaces of measurable operators, J. Funct. Anal., 244, No. 2, 488-503.

[183] Mao, Y.-H. (2008) General Sobolev type inequalities for symmetric forms, J. Math. Anal. Appl., 338, No. 2, 1092-1099.

[184] Markov, A. (1884) On Certain Applications of Algebraic Continued Fractions, Thesis, St. Petersburg.

[185] Matic, M., Pecaric, J. and Ujevic, N. (2001) Weighted version of multivariate Ostrowski type inequalities, Rocky Mountain J. Math., 31, No. 2, 511-538.

[186] Mitrinovic, D.S., Pecaric, J.E. and Fink, A.M. (1991) Inequalities Involving Functions and Their Integrals and Derivatives, Mathematics and its Applications (East European Series), 53, Kluwer Academic Publishers Group, Dordrecht.

[187] Mitrinovic, D.S., Pecaric, J.E. and Fink, A.M. (1993) Classical and New Inequalities in Analysis, Kluwer Academic, Dordrecht.

[188] Mitrinovic, D.S., Pecaric, J.E. and Fink, A.M. (1994) Inequalities for Functions and their Integrals and Derivatives, Kluwer Academic Publishers, Dordrecht. 
[189] Mond, B., Pecaric, J. and Peric, I. (2006) On reverse integral mean inequalities, Houston J. Math., 32, No. 1, 167-181.

[190] Mulholland, H. and Rogers, C. (1958) Representation theorems for distribution functions, Proc. London Math. Soc., 8, 177-223.

[191] Nagy, B. (1974) On cosine operator functions in Banach spaces, Acta Scientiarum Mathematicarum Szeged, 36, 281-289.

[192] Nagy, B. (1977) Approximation theorems for cosine operator functions, Acta Mathematica Academiae Scientiarum Hungaricae, 29 (1-2), 69-76.

[193] Necaev, I.D. (1973) Integral inequalities with gradients and derivatives, Soviet. Math. Dokl., 22, 1184-1187.

[194] Olech, C. (1960) A simple proof of a certain result of Z. Opial, Ann. Polon. Math., 8, 61-63.

[195] Opial, Z. (1960) Sur une inegalité, Ann. Polon. Math., 8, 29-32.

[196] Ostrowski, A. (1938) Über die Absolutabweichung einer differentiebaren Funktion von ihrem Integralmittelwert, Comment. Math. Helv., 10, 226-227.

[197] Pachpatte, B.G. (2000) On an inequality of Ostrowski type in three independent variables, J. Math. Anal. Appl., 249, No. 2, 583-591.

[198] Pachpatte, B.G. (2001) An inequality of Ostrowski type in n independent variables, Facta Univ. Ser. Math. Inform., No. 16, 21-24.

[199] Pachpatte, B.G. (2002) On multivariate Ostrowski type inequalities, JIPAM, J. Inequal. Pure. Appl. Math., 3, No. 4, Article 58, 5 pp. (electronic).

[200] Pachpatte, B.G. (2002) On Grüss type inequalities for double integrals, J. Math. Anal. Appl., 267, 454-459.

[201] Pachpatte, B.G. (2003) New weighted multivariate Grüss type inequalities, electronic Journal: Journal of Inequalities in Pure and Applied Mathematics, http://jipam.vu.edu.au/, Volume 4, Issue 5, Article 108.

[202] Pachpatte, B.G. (2005) Inequalities similar to Opial's inequality involving higher order derivatives, Tamkang J. Math., 36, No. 2, 111-117.

[203] Pachpatte, B.G. (2005) A note on Opial type finite difference inequalities, Tamsui Oxf. J. Math. Sci., 21, No. 1, 33-39.

[204] Pachpatte, B.G. (2005) Mathematical Inequalities, North Holland Mathematical Library, 67, Elsevier B. V., Amsterdam.

[205] Pachpatte, B.G. (2006) Integral and Finite Difference Inequalities and Applications, North-Holland Mathematics Studies, 205, Elsevier Science B. V., Amsterdam.

[206] Pachpatte, B.G. (2006) On Chebyshev-Grüss type inequalities via Pecaric's extension of the Mongomery identity, Journal of Inequalities in Pure and Applied Mathematics, http://jipam.vu.edu.au/, Vol. 7, Issue 1, Article 11.

[207] Pachpatte, B.G. (2007) Some new Ostrowski and Gr üss type inequalities, Tamkang J. Math., 38, No. 2, 111-120.

[208] Pachpatte, B.G. (2007) New inequalities of Ostrowski-Grüss type, Fasc. Math., No. 38, 97-104.

[209] Pachpatte, B.G. (2007) On a new generalization of Ostrowski type inequality, Tamkang J. Math., 38, No. 4, 335-339.

[210] Pachpatte, B.G. (2007) New generalization of certain Ostrowski type inequalities, Tamsui Oxf. J. Math. Sci., 23, No. 4, 393-403.

[211] Pachpatte, B.G. (2007) New discrete Ostrowski-Grüss like inequalities, Facta. Univ. Ser. Math. Inform., 22, No. 1, 15-20.

[212] Pachpatte, B.G. (2008) A note on Grüss type inequalities via Cauchy's mean value theorem, Math. Inequal. Appl., 11, No. 1, 75-80. 
[213] Pecaric, J.E. (1980) On the Cebyshev inequality, Bul. Sti. Tehn. Inst. Politehn. "Traian Vuia" Timisoara, 25 (39), No. 1, 5-9.

[214] Pecaric, J. and Peric, I. (2006) A multidimensional generalization of the LupasOstrowski inequality, Acta Sci. Math. (Szeged), 72, 65-72.

[215] Pecaric, J.E., Proschan, F. and Tong, Y.L. (1992) Convex Functions, Partial Orderings and Statistical Applications, Mathematics in Science and Engineering, 187, Academic Press, Inc., Boston, MA.

[216] Pecaric, J. and Vukelic, A. (2006) Milovanovic-Pecaric-Fink inequality for difference of two integral means, Taiwanese J. Math., 10, No. 4, 933-947.

[217] Peralta, A.M. and Palacios, A.R. (2001) Grothendieck's inequalities revisited, in: Recent Progress in Functional Analysis, (Valencia, 2000), 409-423, North-Holland Math. Stud., 189, North-Holland, Amsterdam.

[218] Plotnikova, E.A. (2008) Integral representations and the generalized Poincaré inequality on Carnot groups, (Russian) Sibirsk. Mat. Zh., 49, No. 2, 420-436.

[219] Polya, G. and Szego, G. (1951) Isoperimetric Inequalities in Mathematical Physics, Annals of Mathematics Studies, No. 27, Princeton University Press, Princeton, N. J.

[220] Rafig, A. and Zafar, F. (2007) New bounds for the first inequality of Ostrowski-Grüss type and applications in numerical integration, Nonlinear Funct. Anal. Appl., 12, No. $1,75-85$.

[221] Richter, H. (1957) Parameterfreie Abschätzung und Realisierung von Erwartungswerten, Blätter der Deutschen Gesellschaft für Versicherungsmathematik, 3, $147-161$.

[222] Riesz, F. (1911) Sur certaines systèmes singuliers d'équations integrales, Ann. Sci. Ecole Norm. Sup., 28, 33-62.

[223] Rogers, L.J. (1888) An extension of a certain theorem in inequalities, Messenger of Math., 17, 145-150.

[224] Royden, H.L. (1968) Real Analysis, Second edition, Macmillan, New York, London.

[225] Sababheh, M. (2007) Two-sided probabilistic versions of Hardy's inequality, $J$. Fourier Anal. Appl., 13, No. 5, 577-587.

[226] Schumaker, L. (1981) Spline Functions Basic Theory, Wiley, New York.

[227] Schwartz, L. (1967) Analyse Mathematique, Paris.

[228] Selberg, H.L. (1940) Zwei Ungleichungen zur Ergänzung des Tchebycheffschen Lemmas, Skand. Aktuarietidskrift, 23, 121-125.

[229] Shen, Z. and Zhao, P. (2008) Uniform Sobolev inequalities and absolute continuity of periodic operators, Trans. Amer. Math. Soc., 360, No. 4, 1741-1758.

[230] Shilov, G. (1974) Elementary Functional Analysis, The MIT Press Cambridge, Massachusetts.

[231] Sofo, A. (2002) Integral inequalities of the Ostrowski type, JIPAM, J. Inequal. Pure Appl. Math., 3, No. 2, Article 21, 39 pp. (electronic).

[232] Sova, M. (1966) Cosine Operator Functions, Rozprawy Matematyczne, XLIX, Warszawa.

[233] Spiegel, M.R. (1963) Advances Calculus, Schaum's Outline Series, McGraw-Hill Book Co., New York.

[234] Stankovic, B. (1996) Taylor Expansion for generalized functions, J. of Math. Analysis and Appl., 203, 31-37.

[235] Stević, S. (2007) Area type inequalities and integral means of harmonic functions on the unit ball, J. Math. Soc. Japan, 59, No. 2, 583-601.

[236] Sulaiman, W.T. (2008) On a reverse of Hardy-Hilbert's integral inequality in its general form, Int. J. Math. Anal. (Ruse), 2, No. 1-4, 67-74. 
[237] Troy, W.C. (2001) On the Opial-Olech-Beesack inequalities, USA-Chile Workshop on Nonlinear Analysis, Electron. J. Diff. Eqns., Conf., 06, 297-301. http://ejde.math.swt.edu or http://ejde.math.unt.edu

[238] Tseng, K.-L., Hwang, S.R. and Dragomir, S.S. (2008) Generalizations of weighted Ostrowski type inequalities for mappings of bounded variation and their applications, Comput. Math. Appl., 55, No. 8, 1785-1793.

[239] Watanabe, K., Kametaka, Y., Nagai, A., Takemura, K. and Yamagishi, H. (2008) The best constant of Sobolev inequality on a bounded interval, J. Math. Anal. Appl., 340, No. 1, 699-706.

[240] Wen, J.J. and Gao, C.B. (2008) The best constants of Hardy type inequalities for $p=-1$, J. Math. Res. Exposition, 28, No. 2, 316-322.

[241] Wen, J.J. and Wang, W.-I. (2007) Chebyshev type inequalities involving permanents and their applications, Linear Algebra Appl., 422, No. 1, 295-303.

[242] Whittaker, E.T. and Watson, G.N. (1927) A Course in Modern Analysis, Cambridge University Press.

[243] Widder, D.V. (1928) A Generalization of Taylor's Series, Transactions of AMS, 30, No. 1, 126-154.

[244] Willett, D. (1968) The existence - uniqueness theorems for an nth order linear ordinary differential equation, Amer. Math. Monthly, 75, 174-178.

[245] Wong, F.-H., Lian, W.-C., Yu, S.-L. and Yeh, C.-C. (2008) Some generalizations of Opial's inequalities on time scales, Taiwanese J. Math., 12, No. 2, 463-471.

[246] Xu, Q. (2006) Operator-space Grothendieck inequalities for noncommutative $L_{p}$-space, Duke Math. J., 131, No. 3, 525-574.

[247] Yang, G.S. (1982) Inequality of Opial-type in two variables, Tamkang J. Math., 13, 255-259.

[248] Yeh, C.-C. (2008) Ostrowski's inequality on time scales, Appl. Math. Lett., 21, No. 4, 404-409.

[249] Zhang, Q.S. (2008) A uniform Sobolev inequality for Ricci flow with surgeries and applications, C. R. Math. Acad. Sci. Paris 346, No. 9-10, 549-552.

[250] Zhao, C.-J. and Cheung, W.-S. (2008) On multivariate Grüss inequalities, J. Inequal. Appl., Art. ID 249438, 8 pp.

[251] Ziemian, B. (1988) Taylor Formula for Distributions, Dissertationes Math. (Rozprawy Mat.), 264, 56 pp.

[252] Ziemian, B. (1989) The Melin transformation and multidimensional generalized Taylor expansions of singular functions, J. Fac. Sci. Univ. Tokyo Sect. IA Math., 36, No. 2, 263-295.

[253] Ziemian, B. (1990) Generalized Taylor expansions and theory of resurgent functions of Jean E'calle, in: Generalized Functions and Convergence (Katowice, 1988), 285-295, World Sci. Publ., Teaneck, NJ. 


\section{List of Symbols}

$\begin{array}{ll}\|\cdot\|_{p}, L_{p} \text { norm, } 17 & \frac{|\cdot|, 150}{B(0, R)}, 141 \\ \|\cdot\|_{\infty}, L_{\infty} \text { norm, } 5 & \operatorname{Lip}(\Omega) \bigcap C_{0}(\Omega), 96 \\ C^{n}([a, b]), n \text { times continuously } & \mathbb{R}^{N}, 140 \\ \text { differentiable functions, } 5 & \mathbb{C}, 241 \\ \|\cdot\|_{1}, L_{1} \text { norm, 47 } & B U C(\mathbb{R}), 206 \\ B_{k}, \text { Bernoulli polynomial, } 21 & D\left(A^{r}\right), 188 \\ B_{k}^{*} \text {, Bernoulli related periodic } & C(t), 249 \\ \text { functions, 21 } & S(t), 249 \\ \omega_{1}, \text { modulus of continuity, } 49 & \mathcal{L} \int, 261 \\ \|\cdot\|_{q}, L_{q} \text { norm, 17 } & \mathcal{R} \int, 261 \\ B(0, R), \text { ball in } \mathbb{R}^{N}, 99 & (\mathcal{R}-\mathcal{S}) \int, 261 \\ S^{N-1}, \text { unit sphere in } \mathbb{R}^{N}, 99 & m(B), 271 \\ \|f\|_{L i p}, \text { Lipschitz constant, } 100 & T(g, h), 280 \\ W^{1, \infty}(\Omega), \text { Sobolev space, } 94 & W_{\text {loc }}^{1,1}\left(\mathbb{R}^{n}\right), 294 \\ \nabla, \text { gradient, 110 } & L_{l o c}^{p}(\Omega), 294 \\ \text { Vol, volume, 110 } & D^{\prime}(\Omega), 294 \\ D^{\alpha}, \text { distributional derivative, } 100 & D(\Omega), 294 \\ W^{n, \infty}(\Omega), 100 & W^{m, p}(\Omega), 295 \\ W^{n, \infty}(\Omega) \cap C_{0}^{n-1}(\Omega), 106 & P_{W}(x, t), 331 \\ \omega_{N}, 93 & \end{array}$


This page intentionally left blank 


\section{Index}

\author{
Absolutely continuous, 12 \\ asymptotically attained, 111 \\ attained inequality, 143 \\ ball in $\mathbb{R}^{N}, 132$ \\ Banach algebra, 187 \\ Banach space, 187 \\ Bernoulli polynomials, 305 \\ Bernoulli numbers, 305 \\ best constant, 229 \\ boundary conditions, 29 \\ boundary, 271 \\ Cauchy-Schwarz inequality, 23 \\ Chebychev functional, 333 \\ Chebychev's inequality, 283 \\ Chebyshev-Grüss type inequality, 331 \\ compact and convex, 29 \\ Cosine and Sine operator functions, \\ 197 \\ diffusion equation, 192 \\ Dirichlet-Poincaré like inequality, 219 \\ distribution, 293 \\ distributional derivative, 295 \\ distributional Taylor formula, 293 \\ Euclidean domain, 99 \\ Euclidean norm, 109 \\ Euler-type identity, 342 \\ extended complete Tschebyshev \\ system, 125
}

Fink identity, 305

general Taylor-Widder formula, 127

generalized Euler type identity, 306

generalized radial derivatives of

Widder type, 125

Green's function, 171

Grüss inequality, 319

Hardy-Opial type inequality, 261

Hölder's inequality, 173

infinitesimal generator, 188

initial value problem, 171

integral means inequality, 341

Korkine's identity, 280

Linear Differential operator, 171

Lipschitz constant, 94

mixed partial, 271

modulus of continuity, 49

Montgomery identity, 331

multivariate Euler type identity, 39

multivariate Fink identity, 367

multivariate Grüss inequality, 365

multivariate means inequality, 357 ,

358

multivariate Ostrowski inequality, 365

multivariate Taylor formula, 285

multivariate trapezoid and midpoint rules, 27 
Neumann-Poincaré like inequality, 232

non-radial, 109

Opial inequality, 149

Opial type inequality, 150

Ostrowski inequality, 93

Ostrowski type inequality, 383

Poincaré inequality, 229

Poincaré like inequality, 209

polar method, 109

radial function, 109

Riemann-Stieltjes integral, 261

remainder, 275

reverse inequality, 209 semigroup, 244

seminorm, 100

sharp inequality, 125

Sobolev like inequality, 215

Sobolev space, 94

spherical shell, 332

surface area, 332

Taylor formula, 198

test function, 294

unit sphere, 332

vector valued function, 188, 229

vector valued Riemann integral, 230

weighted Peano kernel, 331 